\title{
A THEORY FOR THE GRAVITATIONAL POTENTIALS OF SPHEROIDAL STELLAR SYSTEMS \\ AND ITS APPLICATION TO THE GALAXY
}

\author{
An Addendum
}

(Received October 5, 1977)

The published version of our recent paper (Astrophysics and Space Science 47, 299, 1977) failed to include (through no fault of the authors) a note in the manuscript acknowledging the priority of the work of Miyamoto and Nagai (Astr. Soc. Japan 27, 533, 1975), although this reference was included in the published version. This regrettable omission has caused us considerable pain and embarrassment. It is therefore our object to reacknowledge the priority of the aforementioned work.

M. Clutton-Brock

K. A. INNANEN

K. A. PAPP 